\title{
Видовая «неопределенность» двувидовых глаголов как следствие морфемной немаркированности
}

\author{
ЛАСЛО ЯСАИ \\ JÁsZAY László, ELTE BTK Orosz Nyelvi és Irodalmi Tanszék, H-1088 Budapest, Múzeum krt. 4/D. \\ E-mail: jaszay.laszlo@btk.elte.hu
}

(Received: 3 January 2017; accepted: 10 March 2017)

\begin{abstract}
The author analyzes biaspectual verbs with borrowed roots which have prefixed perfective or suffixed imperfective correlates. The analysis focuses on the change (the weakening or loss) of biaspectual semantics of these verbs.
\end{abstract}

Keywords: aspectology, Russian, biaspectual verbs, perfective and imperfective contexts

1. О месте двувидовости в исследовании глагольного вида. В системе видов, - пишет А. Н. Тихонов, - двувидовые глаголы образуют особую и весьма специфическую подсистему (Тихонов 1998: 176). Принимая эту точку зрения, мы считаем лишним останавливаться на дискуссии о том, представляет ли существование двувидовых глаголов (иначе: биаспективов) системное явление или же маргинальное, более того, аномалию в видовой системе русского глагола. В центре нашего внимания стоит вопрос о том, насколько труден последовательный учет синхронического аспекта при описании двувидовых глаголов. Несмотря на то, что грамматика, в отличие от лексики, обычно характеризуется относительной устойчивостью, более ограниченной возможностью изменения, в явлении глагольной двувидовости зачастую обнаруживается именно переходное состояние «нестабильности». Речь идет о том, что в значительной части биаспективов наблюдается немало функциональных особенностей, характеризующихся состоянием постепенного изменения, так как - в случае возможности дальнейшей деривации производящий исходный глагол, расцениваемый как двувидовой, утрачивает (начинает утрачивать или практически уже утратил) одну из своих видовых характеристик: при префиксации, т. е. при появлении подлинного перфективного коррелята - значение СВ (см. анализировать $\rightarrow$ проанализировать), при суффиксации, т. е. при появлении подлинного имперфективного коррелята - значение НСВ (см. арестовать $\rightarrow$ арестовывать).

Наличие переходного состояния влечет за собой несколько «неприятных» последствий с точки зрения изучения и адекватного описания глагольного вида - например, 1) существуют биаспективы, которые неодинаковы в своем функционировании; 2) изменения относительно видовой характеристики биаспективов не всегда отражаются (или же по-разному отражаются) в словарях (см., в частности, ГороБец 2009); 3) при сравнительно быстром 
изменении видовой семантики биаспектива словари своими пометами (сов. и несов.) несколько отстают от реального употребления данного глагола в перфективных или имперфективных контекстах (например, глагол арестовать, в сущности, превратился в перфектив за несколько десятилетий - об этом см. ниже, под 3.1.1). Такого рода несоответствие в аутентичных источниках является особенно мешающим фактором, если двувидовые глаголы употребляются не носителем языка («чувствующим» данное изменение), а иностранцем, который, не зная точную видовую характеристику какого-либо глагола, обращается за справкой к толковому или двуязычному словарю. Но при этом в части случаев возможно, что один и тот же глагол в том или ином словаре снабжен неодинаковой пометой касательно видовой информации (см., например, глаголы анализировать и арестовать). Говоря о двувидовых глаголах, при анализе двойственной характеристики выражения видового значения в дальнейшем мы оставим без внимания как причастные, так и деепричастные формы глагола, у которых, конечно, сохраняется формальное различие противопоставления, тем самым выражены и признаки соотносительности (ср. оппозиции типа арестуемыц - арестованный, арестуюший - арестовавиий, арестуя - арестовав и т. д.). Эти формы, однако, требуют отдельного рассмотрения, в частности, и потому, что «видовые значения причастных форм более устойчивы, чем в остальных формах двувидовых глаголов» (Тихонов 1998: 187).

1.1. В первом теоретическом приближении общая характеристика биаспективов представляется достаточно тривиальной: морфологический синкретизм позволяет истолкование данного глагола в значении обоих видов. Это значит, что видовое значение основного набора парадигматических форм глагола (т. е. форм лица, числа, времени, наклонения и формы инфинитива) определяется в контексте. С другой стороны, однако, именно в одном из теоретических аспектов возможны по меньшей мере два разных подхода к интерпретации двувидовости:

1) Биаспектив представляет собой омонимичность в видовом противопоставлении, т. е. формальное совпадение собственно двух глаголов - глагола СВ и глагола НСВ. В современной аспектологии этого принципа придерживается Е. А. Горобец: «Двувидовые глаголы - это пары омонимичных глаголов, каждый из которых имеет свои формообразовательные и сочетаемостные особенности» (ГороБЕц 2007: 266). Польза такой трактовки очевидна при реализации наглядного лексикографического представления биаспективов: в словарных статьях двувидовых глаголов автор предлагает отдельно описывать и иллюстрировать примерами глагол СВ и глагол НСВ. Однако, как справедливо отмечает Горобец, при такой трактовке традиционный термин «двувидовой глагол» оказывается неудачным, ведь, как пишет она, «одновременно глагол не может быть и несовершенного, и совершенного вида» (ГОРОБЕц 2007: 268). О «видовой омонимии» двувидовых глаголов, хотя лишь вскользь, упоминают и другие аспектологи (ср. ЧЕРтковАЧАНГ 1998: 13, ШЕЛЯкИн 2008: 120). 
2) Отсутствие морфологического различия и исключительно контекстуальная реализация значений СВ и НСВ естественным образом позволяет более традиционное понимание, согласно которому одна и та же глагольная форма потенциально содержит в себе как перфективное, так и имперфективное значение. В нашем понимании речь идет не о «нулевом виде» или о «безвидовости» глагола (как самостоятельной единицы), тем не менее не без основания можно предположить, что из морфемной немаркированности значений СВ и НСВ следует и их «неопределенная» или менее определенная видовая характеристика. При изложении данной проблематики нам ближе именно такая интерпретация двувидовости. Она получает обоснование, как увидим в дальнейшем, если сопоставить функционирование двувидового глагола и его аспектуально однозначного приставочного или суффиксального деривата. Кроме того, двувидовой характер русского глагола, как нам кажется, небезынтересно осветить и на примере некоторых венгерских глаголов. В проведении такой параллели нет ничего особенного, если учесть, что в венгерском языке, в котором также существует превербная (т. е. префиксальная) перфективация, видовое значение выражается преимущественно на уровне предложения (см. Ясаи 1998), подобно тому, как оно выражается в случае двувидовых глаголов в славянских языках. Поэтому здесь мы сделаем краткий экскурс.

Нижеследующие беспревербные глаголы (вроде «биаспективы») в венгерском языке естественным образом получают то имперфективное, то перфективное прочтение, в зависимости от значения соотнесенного обстоятельства времени, а также от отношений одновременности или последовательности. Это находится в точном соответствии со способом выражения вида при употреблении русских биаспективов. Приведем несколько примеров с такими обстоятельствами времени, с помощью которых создается имперфективное или перфективное значение:

1) portalanit ('обеспылить /обеспыливать'): Egész nap portalanítottuk a bútorokat - Néhány óra alatt portalanítottuk az összes bútort;

2) lomtalanit ('очистить/очищать от хлама'): Órákon át lomtalanítottuk a lakást - Néhány óra alatt lomtalanítottuk a lakást;

3) szinkronizál (filmet) ('дублировать/сдублировать фильм'): Egész nap szinkronizálták a filmet - Egy nap alatt szinkronizálták a filmet.

На самом деле, таким же образом ведут себя и беспревербные глаголы с объектом создаваемым:

4) Egész nap írt egy levelet ('Она весь день писала письмо') - Egy óra alatt írt egy levelet ('Она за час написала письмо') (ср. KIEFER 2006: 62-63).

Учет венгерского языка, в котором вид/аспект является в первую очередь синтаксической категорией, может восприниматься одним из аргументов в пользу того, чтобы усмотреть в явлении двувидовости русского глагола меньшую степень видовой определенности. Мы полагаем, что именно этим фактом объясняются некоторые противоречивые данные касательно видовой информации русского глагола. Например, тогда как в словарях глагол 
транслировать приводится в качестве двувидового, в книге М. Ю. Чертковой указано, что этот глагол имеет только значение НСВ (ЧЕРтковА 1996: 106). В статье Е. А. Горобец обращается внимание на непоследовательность при выделении некоторых двувидовых глаголов с иноязычной основой в разных словарях (см., например, бальзамировать НСВ, с одной стороны, и бальзамировать НСВ и СВ, с другой) (ГОРОБЕц 2009: 38).

В специальной литературе явление двувидовости описывалось, помимо стремления к комплексности (см. Тихонов 1998: 176-242), и при выделении разных аспектов - с акцентировкой развития системы двувидовых глаголов (Мучник 1966), распределения глагольных основ по их происхождению ${ }^{1}$ (АвиловА 1968, Шелякин 1979), с учетом лексикографической трактовки данныХ глаГолов (АПРЕСян 1997, ГОРОБЕц 2011) и с фокусировкой на функциональном аспекте (ЧЕРтковА-ЧАНГ 1998, ЗАЛИЗНяк-МИКАЭЛЯН-ШМЕЛЕВ 2015: 82-87). При разноаспектном исследовании данной темы Е. А. Горобец придает особое значение, в частности, и тому, что биаспективы целесообразно описывать как соотносительные омонимичные глаголы с противоположным видовым значением (ГоРОБЕц 2007, ГоРОБЕц 2014).

1.2. В нашей статье будут анализироваться только глаголы с заимствованной основой. При этом проблема двувидовости затрагивается лишь в том случае, если при биаспективе появляется коррелят определенного вида (СВ или $\mathrm{HCB}$ ), и, следовательно, в семантике производящего глагола одно из потенциально наличествующих видовых значений может оттесняться на задний план. Уже предварительно заметим, что такое изменение в видовой семантике глагола возможно, но оно не обязательно происходит во всех биаспективах, утрата одного из видов наблюдается далеко не всегда. В одних случаях, как увидим ниже, переход биаспектива в глагол определенного вида можно считать практически завершенным процессом, другие же биаспективы, несмотря на аспектуально значимую (префиксальную или суффиксальную) деривацию, по-прежнему сохраняют характер двувидовости. И, конечно, наблюдается и неполное сохранение двувидовости, которая не охватывает все грамматические формы глагола. При характеристике глаголов мы преследуем принцип «динамической синхронии», одновременно учитывающей как современное состояние данного явления, так и тенденцию его изменения.

Прежде чем приступить к анализу биаспективов, следует исключить из дальнейшего рассмотрения круг действительно простых случаев явления двувидовости: это те случаи, когда имеет место полная двувидовость (двувидовость во всех грамматических формах глагола), как, например, у глаголов кодифицировать, ликвидировать, реформировать, приватизировать, использовать, исследовать, обследовать, завещать, казнить и у глагола бежать

\footnotetext{
${ }^{1}$ Большинство двувидовых глаголов, как известно, заимствовано из разных европейских языков. Их число постоянно пополнялось и продолжает расти и ныне (например, тестировать, либерализовать, сканировать, спонсировать и др.), но в ограниченном количестве существуют и биаспективы русского (например, велеть, казнить, обещать) и старославянского происхождения (например, образовать, исследовать, использовать).
} 
в значении 'совершать / совершить побег'. Простыми можно считать названные здесь глаголы потому, что они в самом деле совмещают значения противоположных видов во всех своих грамматических позициях, причем новые дериваты как соотносительные перфективы или имперфективы от них не образуются.

2. О префиксации двувидовых глаголов. Как уже указывалось, при префиксации двувидовость устраняется не сразу, более того, утрата семантического потенциала СВ в исходном глаголе имеет место не во всех случаях. Вначале приведем диагностические контексты, которые показывают, что с появлением приставочного варианта при бесприставочном двувидовом глаголе двувидовость автоматически не снимается - исходный глагол может быть заместителем производного глагола СВ в перфективном контексте, ср.:

(1) Художник проиллюстрировал (иллюстрировал) книгу за два дня.

(2) Он сблокировал (блокировал) все выходы за час.

(3) Пассажир не успел закомпостировать / прокомпостировать (компостировать) свой билет.

(4) Я вас об этом обязательно проинформирую (информирую).

(5) Наконец докладчик просуммировал (суммировал) сказанное.

С другой стороны, судя по тенденции употребления приведенных здесь биаспективов, конечно, можно прогнозировать, что начавшийся процесс утраты значения СВ в бесприставочном глаголе ранее или позднее завершится, и тогда надо будет говорить исключительно о видовой парности. Правда, парность типа иллюстрировать-проиллюстрировать при наличии представленной здесь конкуренции не должна отрицаться, своеобразие такого рода соотносительности состоит именно в том, что факт видовой парности сосуществует с состоянием двувидовости.

Видимо, следующие примеры свидетельствуют именно о завершении изменения, начавшегося с появления префиксации - несмотря на то, что в некоторых словарях данное грамматическое изменение еще не отражается (т. е. глаголы по-прежнему зафиксированы как двувидовые), ср.:

(6) За это время исследователь проанализировал ('анализировал) все данные эксперимента.

(7) Мы проанкетируем ('анкетируем) всех информантов, потом опубликуем результаты.

(8) Мы решили продемонстрировать ('демонстрировать) результаты эксперимента.

(9) Партизаны заминировали ('минировали) все поле.

(10) Ученику удалось метко охарактеризовать ('характеризовать) главного героя романа.

В свете приведенных примеров видно, насколько искажается реальная картина употребления, если приведенные в скобках бесприставочные глаголы расценены как двувидовые глаголы. В то же время в изданиях самого 
доступного толкового словаря эти (и еще и другие спорные) глаголы снабжены пометой сов. и несов. (см. ОЖЕГОВ-ШВеДОВА 1998). Из спорных случаев (ср. оперировать, реставрировать, ретушировать) для иллюстрации выделим еще употребительный глагол оперировать, который в современном состоянии языка без каких-либо оговорок также трудно представить в перфективном контексте:

(11) Вчера успешно прооперировали больного (ср. ?оперировали).

(12) В день привоза прооперировали всех раненых (ср. ?оперировали).

(13) В клинике удалось прооперировать и спасти раненную собаку (ср. ?оперировать).

На основе приведенных выше перфективных контекстов (число которых нетрудно умножить) можно сделать только такой вывод, что, в сущности, эти бесприставочные глаголы уже утратили свой двувидовой характер и как глаголы НСВ входят в видовую пару с соответствующим приставочным дериватом СB.

3. О суффиксальной имперфективации двувидовых глаголов. Размышления автора по этому вопросу недавно были высказаны на конференции в Воронеже (ЯсАи 2016: 364-367). В настоящей статье мы изложим подробнее свою точку зрения на данную проблематику. Прежде всего следует подчеркнуть, что принципиальная возможность имперфективации биаспективов зависит от места ударения: расширение основы биаспективов на -овать с помощью суффикса -bва- возможно только при ударном конечном гласном. Глаголы же на -ировать и -ировать исключены из процесса имперфективации (см. эвакуировать, делегировать, саботировать и др.). В то же время надо заметить, что при конечном ударении биаспектива имперфективация глагола реализуется не обязательно, данное условие представляет лишь потенциальную возможность образования, к которому система видов часто прибегает в ходе своего развития. Среди двувидовых глаголов на -овать с ударным конечным гласным есть и такие, которые устойчиво противостоят имперфективации (независимо от происхождения - иноязычного, как титуловать, презентовать или славянского, как даровать). Указанными здесь фактами объясняется, что в количественном отношении суффиксальная имперфективация двувидовых глаголов уступает префиксальной перфективации. По подсчетам М. Ю. Чертковой и П.-Ч. Чанг в русском языке больше, чем 40 двувидовых глаголов, имеющих суффиксальный коррелят НCB, однако в словарях не зафиксированы все образования такого типа (ЧЕРтковАЧАНГ 1998: 22).

3.1. С точки зрения функционирования биаспектива и образованного от него имперфективного коррелята, по нашему мнению, важно учитывать следующие два обстоятельства: 1) Разные исходные двувидовые глаголы неодинаково (то ограниченно, то в полной мере) сохраняют значение НСВ. 2) Соответствующие имперфективы тоже различаются: одни из них могут употребляться и в настоящем времени (организовывать, образовывать, преоб- 
разовывать), другие же выступают практически лишь в формах инфинитива и прошедшего времени (атаковывать, реализовывать, локализовывать). В процессе изменения биаспектива вследствие появления суффиксального деривата мы предлагаем разграничить три этапа, которые ниже будут представлены с опорой на однозначные видовые контексты. Для иллюстрации различаемых стадий в дальнейшем используем всего лишь три глагола, имеющих имперфективный коррелят - это арестовать, организовать и атаковать. С помощью этих глаголов мы репрезентируем разные стадии в изменении двувидового глагола.

3.1.1. Наиболее заметное изменение безусловно произошло в видовой семантике глагола арестовать, который после появления формы apecmoвblвать, как кажется, постепенно утратил значение НСВ и стал глаголом СВ. Тем не менее бросается в глаза, что относительно видовой характеристики глагола арестовать нет единства в грамматиках и словарях. ${ }^{2} \mathrm{O}$ колебании свидетельствует следующий обзор литературы.

В грамматике А. В. Исаченко глагол арестовать еще квалифицирован как двувидовой, у которого образуется «суффиксальный неологизм» арестовывать со значением НСВ. Тем не менее, отмечает автор, нельзя сказать: *его будут арестовать (ИсАчЕНКо 1960: 144, 146). Также в качестве двувидового приводится этот глагол в ССРЛЯ, первый том которого был издан в 1950 году. В отличие от этого, в словарях С. И. Ожегова, начиная уже с 4го издания (ОжЕгов 1960), арестовать отмечен как глагол СВ (так же, как в словарях С. И. Ожегова и Н. Ю. Шведовой). Однако эта точка зрения, как можно полагать, тогда еще не стала общепринятой, так как 20 лет спустя во втором издании МАС глагол арестовать определяется как двувидовой. Правда, «в противоположность» помете в МАС (1981), в новой академической грамматике (издание которой почти совпало со вторым изданием МАС) отмечается, что арестовать следует уже считать глаголом СВ (РГ-1980: 592). Казалось бы, что в лингвистической литературе спорный вопрос о двувидовости или перфективности данного глагола в последнее время окончательно решается в пользу СВ: в статье, специально посвященной двувидовым глаголам (см. ЧЕРтковА-ЧАнг 1998: 32), указывается только на перфективное значение глагола арестовать. Однако в книге Тихонова (вышедшей в свет также в 1998 г.) глагол арестовать по-прежнему трактуется как двувидовой, и к такому выводу можно прийти не только на основе выраженных видовых различий причастными и деепричастными формами (см. Тихонов 1998: 186). В доказательство наличия значения НСВ в глаголе арестовать автор приводит следующее предложение: Именем закона арестую <наст.> вас! (Тихонов 1998: 238). Из контекстов, представленных в словаре Е. А. Горобец для иллюстрации значения НСВ у глагола арестовать, здесь цитируем два примера (ГороБЕц 2014: 69):

\footnotetext{
${ }^{2} \mathrm{C}$ точки зрения учета видовой информации не безразлично, когда вышли в свет данные работы.
} 
(14) Оно, конечно, самому больно смотреть, когда арестуют людишек (А. И. Алдан-Семенов: Красные и белые, 1966-1973).

(15) Когда Нору арестовали, она кричала агентам ФБР: «Да здравствует революция молодежи!» (В. Аксенов: Новый сладостный стиль, 2005).

В связи с представленными данными сделаем следующие замечания:

1) Наше тестирование с русскими респондентами (проведенное в конце 1990-х годов) показало, что глагол арестовать в значении НСВ возможен лишь с некоторыми оговорками в позициях настоящего времени и повелительного наклонения, но, несмотря на принципиальную возможность его употребления, совершенно очевидно, что и в настоящем времени, и в императиве (например, при отрицании) явно преобладают соответствующие формы глагола НСВ арестовывать (ср. ЯСАИ 2005: 179).

2) В вышеприведенном примере - Именем закона арестую вас! - глагол употребляется в перформативном настоящем ( $\approx$ 'вы арестованы'), т. е. в момент произнесения этот акт практически уже осуществлен, арест вступает в силу, и в этой функции безусловно возможна конкуренция арестую / арестовываю, ср. и пример: На крик «Именем закона я вас арестовываю», он ответил... (К. Дюваль: Я - враг индивидуальной собственности). В предложении же Когда Нору арестовали, она кричала агентам... выбор биаспектива, у которого меньшая сила имперфективного значения по сравнению с формой арестовывали, мотивируется, по-видимому, тем, что в данной ситуации имеет место одноразовое (неповторяющееся) действие.

3) Следует усмотреть, что лексикографическая характеристика глагола арестовать оказывается нелегкой задачей: лексикограф должен взвешивать не один аспект при подаче видовой информации. Возникает вопрос: каков минимальный объем двувидовости, в каких пределах можно говорить о глаголе как двувидовом? Где проходит граница между двувидовым глаголом и глаголом СВ? Нам кажется, что на эти вопросы можно дать разные ответы, в зависимости от того, кому адресуется информация. Нет сомнения, что в учебной практике глагол арестовать - парный глагол СВ при apecmoвblвать. В научном же описании как предмет всестороннего анализа арестовать может быть расценен как (сильно ограниченно) двувидовой глагол. А что касается словарной практики, также целесообразно учитывать, на каких пользователей рассчитан данный словарь. Тем не менее в словарной статье представляется существенным указать на то, что глагол арестовать в значении НСВ встречается редко, лишь в устаревшем употреблении. В этом плане хорошим примером служит новый академический словарь (ср. БАС 1: 152).

3.1.2. Из сильно ограниченной двувидовости глагола арестовать следует, что большинство биаспективов, имеющих имперфективный коррелят, в большей мере сохраняет значение НСВ. Переходную стадию в утрате НСВ представляют глаголы организовать, образовать и преобразовать, которые сравнительно часто выступают в значении НCB, но, как показывают примеры, только в позиции настоящего времени и, реже, в повелительном наклонении (например, при отрицании). В отличие от этого, в формах инфинитива 
и прошедшего времени указанные глаголы выражают только значение СВ. Для выражения НСВ служат в этих позициях соответствующие формы имперфективного коррелята. Итак, можно сделать вывод о том, что упомянутые биаспективы характеризуются лишь неполной двувидовостью. Об этом свидетельствуют следующие диагностические контексты:

(16) Наша кафедра регулярно организует конференции (ср. также: организовываem).

(17) Больше не организовывайте таких мероприятий (ср. также: не организуйme).

(18) Наша кафедра регулярно организовывала конференции (ср. *регулярно организовала).

(19) Школа перестала организовывать летние лагеря (ср. *перестала организовать).

(20) Такие экскурсии не стоит организовывать (ср. *организовать).

(21) Будешь организовывать эту встречу или уже раздумал? (ср. *будешь организовать).

В связи с употреблением имперфективного коррелята организовывать и с учетом тенденции изменения следует заметить, что тогда как несколько десятилетий тому назад этот имперфектив в настоящем времени еще считался менее привычным (ср. ГрАудинА 1983: 100-101), то ныне он уже серьезно начинает вытеснять двувидовой глагол и в этой позиции. Об этом свидетельствует и современное словарное представление глаголов организовать, образовать и преобразовать, которые, хотя частично, в новом академическом словаре приводятся уже в качестве парных глаголов СВ при имперфективах организовывать, образовывать и преобразовывать. А что касается возможности употребления названных биаспективов и в настоящем времени, то за исключением глагола организовать на это указывается в рамках словарной статьи данной видовой пары (ср. БАС 14, 15, 16).

3.1.3. Другой тип коррелятивности представляют двувидовой глагол $a m a-$ ковать и его имперфективный дериват атаковывать. В этом случае очевидно даже при первом рассмотрении, что речь идет не о видовой парности, так как, с одной стороны, биаспективом атаковать могут передаваться помимо перфективности и все значения НСВ, с другой стороны, дериват атаковьвать не в состоянии выражать все значения НСВ. Сначала покажем, что, несмотря на наличие имперфектива атаковывать, исходный двувидовой глагол естественным образом выступает в разных типичных имперфективных контекстах.

(22) Атакуют наши форварды, прижимают с первой минуты матча (Из репортажа о футбольном матче).

(23) Когда мы стали атаковать - получился спектакль. Болельщики стали поддерживать игроков (http://sykt24.ru).

(24) Боевики продолжают атаковать мариупольское направление, действуют диверсионно-разведывательные группы (http://hronika.info). 
(25) Террористы продолжают атаковать (http://hronika.info).

(26) Если хотя бы один NPC вас будет атаковать..., то начнут атаковать все другие (http://other-games.ru/publ/s/skyrim/26-1-0-862).

Возникает вопрос: если доказывается, что атаковать - это двувидовой глагол в своем полном объеме (с полной парадигмой значений НСВ), то чем мотивируется его замена в некоторых имперфективных контекстах вариантом атаковывать? Прежде чем ответить на этот вопрос, покажем употребление рассматриваемого имперфектива в контексте:

(27) Потом откуда-то взялись мелкие черные муравьи. Должно быть, из города завезли. Стали атаковывать розетки с вареньем, сахарницу, банки с медом и из-под него (А. Олшанский: Что делать с муравьями?).

(28) Они стали атаковывать бомбардировщика без всяких предосторожностей (А. Калиниченко: В небе Балтики).

(29) Немецкие летчики нащупали уязвимое место кораблей и стали aтаковblвать их сзади (С. и М. Никольские: Муромцы в бою. Подвиги русских авиаторов).

(30) Хакеры продолжают атаковывать ЕP (http://finam.info).

(31) Группы самолетов Ил-2 непрерывно атаковывали вражескую артиллерию, танки, скопления живой силы, расчищая путь наступавшим войскам (С. А. Красовский: Жизнь в авиации 5).

(32) Отдельные эшелоны атаковывали внезапно, как правило, на нормальном фронте (Миддельдорф Эйке: Русская кампания: тактика и вооружение).

(33) Финны в 1941-1944 не только бомбили Дорогу Жизни, но и атаковывали ее с воды... (В. М. Коклюшкин: Приехали!)

(34) Войска Гудериана несколько раз атаковывали позиции дивизии, но всегда их атаки отбивались с большими потерями для них (В. Зайцев: Бои местного значения).

По сопоставлению глагола атаковать в значении НСВ и его деривата атаковывать сделаем три вывода: 1) В прикладном аспекте, в иностранной аудитории дериват атаковывать можно оставить без внимания, поскольку глагол атаковать практически в любой позиции НСВ оказывается уместным. Кроме того, данный имперфектив встречается весьма редко по сравнению с глаголом атаковать (а также, конечно, и с имперфективами типа организовывать). 2) В семантическом аспекте может быть выявлено следующее различие: иногда выбор варианта атаковывать мотивируется тем, что в позициях прошедшего времени и инфинитива (в сочетании с фазовым глаголом) он - в большей мере, чем атаковать в значении НСВ - может подчеркнуть длительную повторяемость действия, неоднократное совершение атак. Это значение выражается и без лексических показателей типа непрерывно, несколько раз, следовательно и сочетание атаковывали внезапно (см. пример 32) изображает действие как повторяющееся. 3) Другая особенность глагола атаковывать состоит в том, что в современном литературном языке этот имперфектив не употребляется в позиции настоящего времени. 


\section{Словари}

БАС = Большой академический словарь русского языка. Т. 1-23. Санкт-ПетербургМосква: «Наука», 2004-2014.

ГОРОБЕЦ 2014 = ГОРОБЕЦ Е. А. Биаспективы в современном русском языке. Словарь. Казань: Издательство Казанского университета, 2014.

МАС = ЕвГЕНьЕВА А. П. (ред.) Словарь русского языка. Т. 1-4. Изд. 2-е, испр. и доп. Москва: «Русский язык», 1981-1984.

ОЖЕГОВ 1960 = ОЖЕГОВ С. И. Словарь русского языка. Изд. 4-е, испр. и доп. Москва: «Государственное издательство иностранных и национальных словарей», 1960.

ОЖЕГОВ-ШВЕДОВА 1998 = ОЖЕГОВ С. И., ШВЕДОВА Н. Ю. Толковый словарь русского языка. Изд. 4-е, доп. Москва: «Азбуковник», 1998.

ССРЛЯ = Словарь современного русского литературного языка. Т. 1-17. МоскваЛенинград: Издательство АН СССР, 1950-1965.

\section{Литература}

АвиловА $1968=$ АвиловА Н. С. Двувидовые глаголы с заимствованной основой в русском литературном языке нового времени. Вопросы языкознания 1968/5: 66-78.

АПРЕСян 1997 = АПРЕСян Ю. Д. Лексикографическая трактовка вида: нетривиальные случаи. В кн.: Труды аспектологического семинара филологического факультета МГУ. Т. 2. Москва: Издательство Московского университета, 1997. 7-20.

ГорОБЕц $2007=$ ГоРОБЕц Е. А. Статус двувидовыХ глаголов в современном русском языке. Ученые записки Казанского университета. Серия «Гуманитарные науки». Т. 149. Кн. 2. Казань, 2007. 263-271.

ГороБЕЦ $2009=$ ГоРОБЕц Е. А. Двувидовые глаголы: количественный состав. Альманах современной науки и образования. № 2. Ч. 2. Тамбов, 2009. 37-40.

ГОРОБЕЦ 2011 = ГОРОБЕЦ Е. А. БиаспективЫ в «Толковом словаре русского языка» (под ред. Н. Ю. Шведовой). Ученье записки Казанского университета. Серия «Гуманитарные науки». Т. 153. Кн. 6. Казань, 2011. 111-118.

ГрАУдиНА 1983 = ГРАУдИНА Л. К. Беседы о русской грамматике. Москва: «Знание», 1983.

ЗАЛИЗНЯК-МИКАЭЛЯН-ШМЕЛЕВ 2015 = ЗАЛИЗНЯк Анна А., МИКАЭЛЯН И. Л., ШМЕЛЕВ А. Д. Русская аспектология: в защиту видовой пары. Москва: «Языки славянской культуры», 2015.

ИСАЧЕНКО 1960 = ИСАЧЕНКО А. В. ГрамматическИй строй русского языка в сопоставлении с словаџким. Братислава: Издательство Словацкой академии наук, 1960.

Мучник 1966 = Мучник И. П. Развитие системы двувидовых глаголов в современном русском языке. Вопросы языкознания 1966/1: 61-75.

РГ-1980 = ШведовА Н. Ю. (ред.) Русская грамматика. Т. 1. Москва: «Наука», 1980.

Тихонов 1998 = Тихонов А. Русский глагол. Проблемы теории и лексикографирования. Москва: «Academia», 1998.

ЧЕРТКОВА 1996 = ЧЕРТкОВА М. Ю. Грамматическая категория вида в современном русском языке. Москва: Издательство Московского университета, 1996.

ЧЕРТКОВА-ЧАНГ 1998 = ЧЕРТКОВА М. Ю., ЧАНГ П.-Ч. Эволюция двувидовых глаголов в современном русском языке. Russian Linguistics 22 (1998): 13-34.

ШЕлякин 1979 = ШЕлякин М. А. О причинах устойчивости двувидовых глаголов в современном русском языке. Вопросы русской аспектологии IV. Tartu, 1979. 3-17. 
ШЕлякин 2008 = ШЕлякин М. А. Категория аспектуальности русского глагола. Москва: «ЛКИ», 2008.

ЯСАИ 1998 = ЯСАИ Л. Особенности выражения видовыХ значений в венгерском языке. В кн.: ЧЕРтковА М. Ю. (ред.) Типология вида. Проблемы, поиски, решения. Москва: «Языки русской культуры», 1998. 508-513.

ЯСАИ 2005 = ЯСАИ Л. Видовые Корреляџии русского Языка в системе грамматических оппозиций. Budapest: ELTE Szláv és Balti Filológiai Intézet, 2005.

ЯСАИ 2016 = ЯСАи Л. О двувидовых глаголах (семантико-функциональный аспект). В кн.: Семантико-функииональная грамматика в лингвистике и лингводидактике. Сборник материалов Всероссийской научно-методической конференщии с международным участием, посвященной 65-летнему юбилею В. Ю. Копрова. Воронеж: «Наука-Юнипресс», 2016. 361-368.

KIEFER 2006 = KIEFER Ferenc: Aspektus és akcióminőség (különös tekintettel a magyar nyelvre). Budapest: Akadémiai Kiadó, 2006. 